\title{
Q (1) Pharmacological and psychotherapeutic interventions for management of obsessive-compulsive disorder in adults: a systematic review and network meta-analysis
}

oa

Lancet Psychiatry 2016; 3: 730-39

Published Online June 15, 2016

http://dx.doi.org/10.1016/ S2215-0366(16)30069-4

See Comment page 695

Division of Psychiatry, University College London, London, UK (P Skapinakis PhD, Prof G Lewis PhD); Department of Psychiatry, University of loannina School of Medicine, University of loannina, loannina, Greece (P Skapinakis); School of Social and Community Medicine, University of Bristol, Bristol, UK (D M Caldwell PhD,

Prof W Hollingworth PhD, PBryden MSc, N J Welton PhD, H Baxter PhD, D Kessler MRCGP);

Department of Postgraduate Medicine, University of Hertfordshire, Hatfield, UK, and Highly Specialised Obsessive-Compulsive Disorder and Body Dysmorphic Disorder Services, Hertfordshire Partnership University NHS Foundation Trust, Hertfordshire, UK

(N A Fineberg MRCPsych); Department of Psychology, University of Bath, Bath, UK (Prof P Salkovskis PhD); and

Centre for Reviews and Dissemination, University of York, York, UK (Prof R Churchill PhD) Correspondence to: Dr Petros Skapinakis, Division of Psychiatry, University College London, London W1T 7NF, UK p.skapinakis@gmail.com

Petros Skapinakis, Deborah M Caldwell, William Hollingworth, Peter Bryden, Naomi A Fineberg, Paul Salkovskis, Nicky J Welton, Helen Baxter, David Kessler, Rachel Churchill, Glyn Lewis

\section{Summary}

Background Several interventions are available for management of obsessive-compulsive disorder in adults, but few studies have compared their relative efficacy in a single analysis. We aimed to simultaneously compare all available treatments using both direct and indirect data.

Methods In this systematic review and network meta-analysis, we searched the two controlled trials registers maintained by the Cochrane Collaboration Common Mental Disorders group for trials published up to Feb 16, 2016. We selected randomised controlled trials in which an active psychotherapeutic or pharmacological intervention had been used in adults with obsessive-compulsive disorder. We allowed all comorbidities except for schizophrenia or bipolar disorder. We excluded studies that focused exclusively on treatment-resistant patient populations defined within the same study. We extracted data from published reports. The primary outcome was symptom severity as measured by the Yale-Brown Obsessive Compulsive Scale. We report mean differences with 95\% credible intervals compared with placebo. This study is registered with PROSPERO, number CRD42012002441.

Findings We identified 1480 articles in our search and included 53 articles (54 trials; 6652 participants) in the network meta-analysis. Behavioural therapy (mean difference $-14 \cdot 48$ [95\% credible interval $-18 \cdot 61$ to $-10 \cdot 23$ ]; 11 trials and 287 patients), cognitive therapy $(-13.36$ [-18.40 to $-8 \cdot 21]$; six trials and 172 patients), behavioural therapy and clomipramine $(-12.97[-19 \cdot 18$ to $-6 \cdot 74]$; one trial and 31 patients), cognitive behavioural therapy and fluvoxamine $(-7 \cdot 50$ [-13.89 to $-1 \cdot 17]$; one trial and six patients), cognitive behavioural therapy $(-5 \cdot 37$ [ $-9 \cdot 10$ to $-1 \cdot 63]$; nine trials and 231 patients), clomipramine $(-4 \cdot 72$ [ -6.85 to $-2 \cdot 60]$; 13 trials and 831 patients), and all SSRIs (class effect $-3 \cdot 49$ [95\% credible interval $-5 \cdot 12$ to $-1 \cdot 81$ ]; 37 trials and 3158 patients) had greater effects than did drug placebo. Clomipramine was not better than were SSRIs (-1.23 [-3.41 to 0.94]). Psychotherapeutic interventions had a greater effect than did medications, but a serious limitation was that most psychotherapeutic trials included patients who were taking stable doses of antidepressants (12 [80\%] of the 15 psychotherapy trials explicitly allowed antidepressants).

Interpretation A range of interventions is effective in the management of obsessive-compulsive disorder, but considerable uncertainty and limitations exist regarding their relative efficacy. Taking all the evidence into account, the combination of psychotherapeutic and psychopharmacological interventions is likely to be more effective than are psychotherapeutic interventions alone, at least in severe obsessive-compulsive disorder.

Funding National Institute for Health Research.

Copyright (C) Skapinakis et al. Open Access article published under the terms of CC BY.

\section{Introduction}

Obsessive compulsive disorder is considered the fourth most common mental disorder in high-income countries and ranks as the tenth leading cause of disability worldwide. ${ }^{1,2}$ It is associated with increased mortality ${ }^{3}$ and can have a substantial impact on quality of life for both patients and family members or carers. ${ }^{2}$ Clomipramine and the SSRIs are currently recommended for pharmacological management of the disease. ${ }^{4}$ Psychotherapies and especially behavioural or cognitive behavioural interventions have been developed ${ }^{5,6}$ and are also recommended.

Previous systematic reviews and meta-analyses have generally compared the efficacy of pharmacological interventions with placebo, not with each other. ${ }^{8-10}$ Psychotherapeutic interventions have typically been compared with a waiting list or other inactive therapy.,11 Only a few studies have directly compared psychotherapeutic with pharmacological interventions or combinations of them, and their results are inconclusive. ${ }^{7}$ In the absence of available head-to-head comparisons, indirect evidence can be used to enhance the existing evidence base. Indirect comparisons between different medications have been done in the past, but statistical methods appropriate for such comparisons were poorly developed at that time. ${ }^{10}$ Network meta-analysis is a method of synthesising information from a network of trials addressing the same question, but involving 
Research in context

\section{Evidence before this study}

During the protocol stage of our project (May 1 to June 30, 2013), we did a scoping search of the literature. We used the two specialised registers of controlled trials maintained and administered by the Cochrane Collaboration Common Mental Disorders Group. We searched the registers using the generic term "condition = obsess ${ }^{*}$ OR compulsi ${ }^{*}$ ", with no language or date restrictions. We found that the latest comprehensive review had been published in 2006 and specific meta-analyses had been published in 2008. Since then, several new trials have been done. Previous systematic reviews and meta-analyses have generally focused on the comparison between antidepressant medications and placebo or psychotherapeutic interventions and a waiting list. Few studies have directly compared the relative efficacy of serotonergic antidepressants versus each other, behavioural-type psychotherapies versus each other, or medications versus psychotherapies. Clinicians are often interested in pragmatic comparisons (Are all SSRIs equally effective? Is clomipramine more effective than are SSRIs? Is cognitive behavioural psychotherapy more effective than are medications?), but these questions have been examined in few studies in the past using statistical methods that have not always taken into account the complexity of such comparisons. We therefore did a network meta-analysis with the aim to simultaneously compare in a single analysis and rank in terms of efficacy all available interventions for management of obsessive-compulsive disorder in adults.

\section{Added value of this study}

We found small differences in efficacy between medications, and the hypothesis of clomipramine being better than SSRIs was not confirmed. Although certain psychotherapies were associated with larger effects than were medications, we underline an important limitation that, in most psychotherapeutic trials, patients who were taking stable doses of antidepressants were not excluded and therefore these therapies cannot be considered as pure monotherapies.

\section{Implications of all the available evidence}

Taking all evidence into account, the combination of psychotherapies with medications is possibly the most effective intervention and clinicians should consider this option more often than at present for patients with severe obsessive-compulsive disorder. Psychotherapy is effective in symptomatic patients taking antidepressant medications, and its effect as monotherapy is not known. Future research should try to differentiate more clearly the effect of medications versus psychotherapy and monotherapy versus combined therapy, avoiding the limitations that we have underlined in this study. different interventions. It aims to combine direct and indirect evidence into a single effect size and rank all available treatments in terms of efficacy, providing estimates for interventions even if they have not been directly compared. This approach has been applied successfully to schizophrenia, bipolar disorder, depression, and certain anxiety disorders (social phobia and generalised anxiety disorder), but not obsessivecompulsive disorder. We therefore did a systematic review and network meta-analysis with the aim to simultaneously compare all available treatments using both direct and indirect data. ${ }^{12} \mathrm{~A}$ more detailed report than this one will be published, and data collected for children and adolescents will also be separately published.

\section{Methods}

\section{Search strategy and selection criteria}

In this systematic review and network meta-analysis, we searched the two controlled trials registers maintained by the Cochrane Collaboration Common Mental Disorders group for trials published up to Feb 16, 2016, by experienced staff of the Cochrane Common Mental Disorders group using their standard methodology. Reports of trials for inclusion in the Group's registers are collated from routine (weekly), generic searches of MEDLINE, Embase, and PsycINFO; quarterly searches of the Cochrane Central Register of Controlled Trials; and review-specific searches of additional databases.
We searched the registers using the generic term "condition $=$ obsess $*$ OR compulsi ${ }^{\star}$ ", with no language restrictions. We included studies in the review if they were randomised controlled trials of adult patients with a diagnosis of obsessive-compulsive disorder. We allowed all comorbidities except for schizophrenia or bipolar disorder. We excluded studies that focused exclusively on treatment-resistant patient populations defined within the same study.

Eligible experimental interventions were all antidepressants $^{7}$ and psychotherapeutic interventions ${ }^{7}$ recommended by current guidelines-ie, behavioural therapy, including exposure and response prevention but not explicit cognitive techniques (such as cognitive restructuring); cognitive therapy, including cognitive restructuring but not explicit behavioural techniques; and cognitive behavioural therapy (CBT). In psychotherapy trials that used both an individual and group format, we extracted data only for groups with the individual format. Eligible control interventions were drug placebo, psychological placebo (any credible psychological intervention that includes only non-specific components of therapy, such as general stress management or relaxation), and any other non-specific psychotherapeutic relationship. Inclusion and exclusion criteria were independently assessed by two reviewers (HB and PSk) and validated by one reviewer (PSk). For studies that were excluded, we noted the main reason for exclusion. 
For OpenBUGS see http://www. openbugs.net

\section{Data analysis}

Data extraction was done independently by two reviewers (HB and PSk) and validated by one reviewer (PSk). We used standardised data extraction Word forms and structured Excel spreadsheets to extract data from published reports. In cases of duplicate data, we selected the manuscript with the largest sample. We also considered preliminary congress abstracts duplicate and did not select them if a full article had been published after the congress. We extracted data for inclusion and exclusion criteria (study design, experimental intervention, control intervention, age range, primary diagnosis, comorbid diagnoses, and use of diagnostic criteria), general details of the study (country, treatment setting, and length of follow-up), details of continuous outcome assessment (number of patients eligible for randomisation, randomised, dropped out, and remaining at the end of study, and baseline, end of treatment, and change from baseline Yale-Brown Obsessive Compulsive Scale [YBOCS] scores, with SDs), and details of the risk

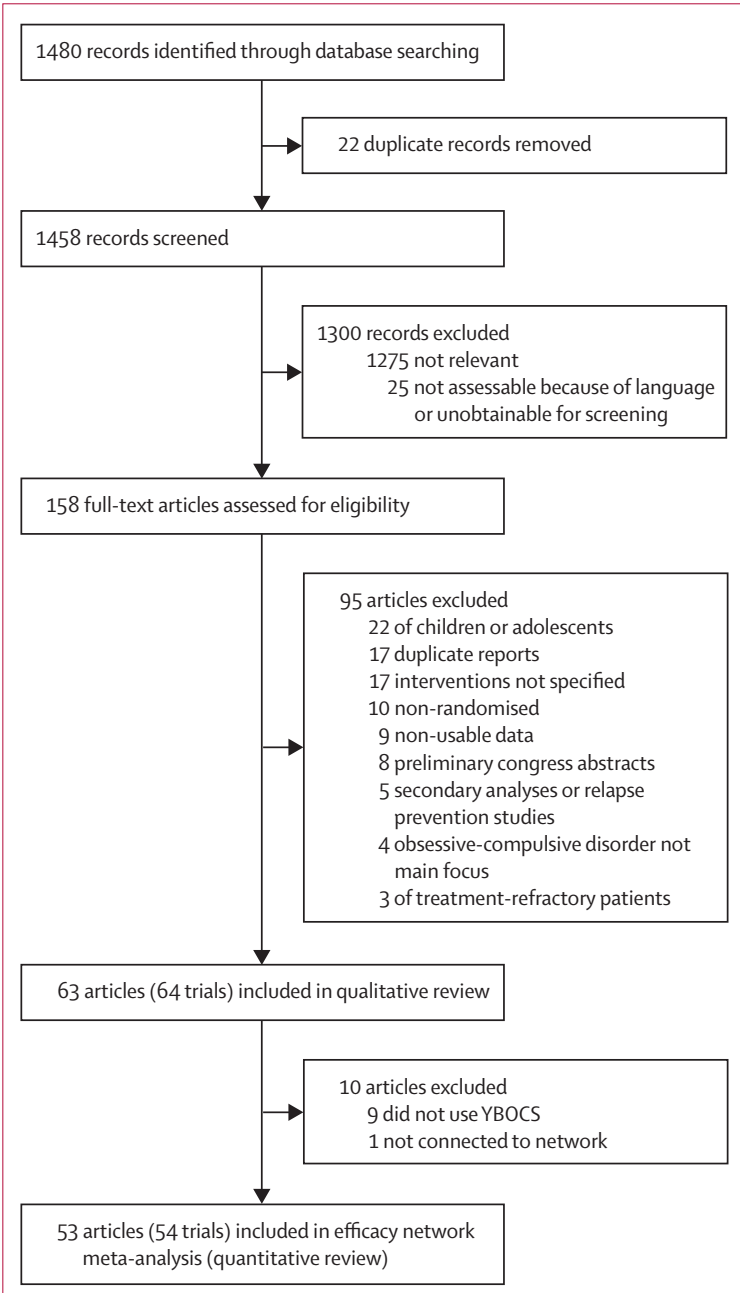

Figure 1: Study selection

YBOCS=Yale-Brown Obsessive Compulsive Scale. of bias assessment (intention-to-treat analysis, use of methods for handling missing data, and dropouts).

For the quantitative synthesis, the primary outcome measure was continuous and it was symptom severity as measured by YBOCS. ${ }^{13}$ Our preferred measure was mean change from baseline score. For studies in which this measure was not reported, we used mean YBOCS scores at the end of study after checking that YBOCS at baseline was balanced across groups. We report mean differences with $95 \%$ credible intervals compared with placebo. We assessed risk of bias using the criteria suggested by the Cochrane Collaboration Handbook. ${ }^{14}$ We included studies with a high risk of bias in the main analysis but did sensitivity analyses to examine the effect of excluding them.

We did pairwise and network meta-analyses for efficacy. We excluded studies that did not use YBOCS. This post-hoc decision was made for two reasons: YBOCS is the only available clinician-rated scale that has been extensively validated in controlled trials worldwide ${ }^{13}$ and use of a single scale allowed us to use the mean difference instead of the standardised mean difference, avoiding the methodological and interpretational difficulties associated with use of standardised mean difference. ${ }^{14}$ Where possible, we derived missing SDs from reported statistics following guidance in the Cochrane Collaboration Handbook..$^{14}$ Where possible, we analysed the intention-to-treat population; otherwise, we used reported results for participants who completed the study.

We did all analyses in a Bayesian framework using OpenBUGS version 3.2.3. We used the random-effect models described by Dias and colleagues, ${ }^{15}$ modified to incorporate an additional class hierarchy, ${ }^{16}$ such that all SSRIs were assumed to be similar, with a common class mean effect and between-SSRI variability about this class mean. We used flat priors for all parameters. We assessed heterogeneity by examining the posterior median of the between-study heterogeneity parameter from the random-effects model. To assess variability within studies, we used what was reported by trial authors. For continuous measures SDs were reported and for ratio measures typically SEs. However, where these statistics were not reported, we used methods recommended by the Cochrane Collaboration Handbook $^{14}$ (eg, estimation of SEs from CIs). We measured goodness of fit with the posterior mean of the residual deviance. To assess inconsistency between direct and indirect evidence, we compared the fit of a model assuming consistency with that of one that relaxes this assumption (unrelated mean-effects model). ${ }^{17}$ We also compared the results of the pairwise meta-analysis with those of the network meta-analysis. All OpenBUGS code is available in the appendix.

Preplanned sensitivity analyses excluded studies at high risk of bias for the following domains: masking of the outcome assessor, incomplete outcome data, and high 
overall attrition or evidence of differential attrition between groups. We present the results both before (ie, the full dataset) and after excluding waiting list controlled trials. These trials are non-masked and evidence exists that they lead to biased results in favour of the active psychotherapeutic interventions..$^{18-20}$ We did separate meta-regressions assuming a common interaction term for the following study-level characteristics: length of trial, publication date, industry sponsorship, and inclusion of patients with current comorbid depression. This study is registered with PROSPERO, number CRD42012002441.

\section{Role of the funding source}

The funder had no role in study design, data collection, data analysis, data interpretation, or writing of the report. The corresponding author had full access to all the data in the study and had final responsibility for the decision to submit for publication.

\section{Results}

We identified 1480 articles in our search and assessed 158 (11\%) full-text articles for eligibility (figure 1). We excluded 95 (60\%) articles and included 64 trials reported in $63(40 \%)$ articles ${ }^{21-83}$ in the qualitative review. A detailed list of the excluded studies is in the appendix. From the 63 articles eligible for inclusion in the network meta-analysis, we excluded ten (16\%): nine $(14 \%)^{22,32,35,36,54,62,73,7,80}$ did not use YBOCS and one $(2 \%)^{47}$ was not connected to the network (details of these studies in appendix), leaving 54 trials reported in 53 (34\%) articles ${ }^{21,23-31,33,34,37-46,48-53,55-61,63-72,74-76,78,79,81-83}$ included in the network meta-analysis (quantitative review). 7302 patients were randomly allocated in the qualitative review; however, 7014 (96\%) were randomly allocated in the network meta-anlysis, with 288 (4\%) excluded. Only 6652 (91\%) contributed to the network meta-analysis since some trials did not report outcomes for all participants.

The 64 trials included in the qualitative review were published over a period of 33 years (1980-2012; table 1; detailed characteristics in appendix). In most psychotherapeutic trials, patients were not excluded if they were taking a stable dose of antidepressants for at least 3 months before inclusion (13 [72\%] of all 18 psychotherapeutic trials and 12 [80\%] of the 15 psychotherapeutic trials included in the network meta-analysis explicitly allowed antidepressants). In these trials, the proportion of patients on antidepressant medication varied, ranging from $13 \%$ to $100 \%$ and, in more than two-thirds of studies with the information available, was $45 \%$ or higher (detailed description in appendix). Patients were not allowed to make dose adjustments during trials, but no specific information was provided on how this criterion had been monitored by authors. Participants had long-standing and severe obsessive-compulsive disorder. Demographic and clinical characteristics of participants were similar across comparisons.

\begin{tabular}{|c|c|c|}
\hline & All trials $(n=64)$ & $\begin{array}{l}\text { Trials eligible for } \\
\text { network } \\
\text { meta-analysis }(n=54)\end{array}$ \\
\hline Eligible patients & 7302 & 7014 \\
\hline Sample size & 66 (31-159) & $81(40-168)$ \\
\hline Eligible arms & 148 & 127 \\
\hline \multicolumn{3}{|l|}{ Number of arms } \\
\hline Two & $51(80 \%)$ & $42(78 \%)$ \\
\hline Three & $6(9 \%)$ & $5(9 \%)$ \\
\hline Four & $7(11 \%)$ & $7(13 \%)$ \\
\hline \multicolumn{3}{|l|}{ Year of publication } \\
\hline $1980-90$ & $10(16 \%)$ & $4(7 \%)$ \\
\hline $1991-2000$ & $27(42 \%)$ & $23(43 \%)$ \\
\hline 2001-12 & $27(42 \%)$ & $27(50 \%)$ \\
\hline \multicolumn{3}{|l|}{ Type of intervention } \\
\hline Medication only & $38(59 \%)$ & $33(61 \%)$ \\
\hline Psychotherapy only & $18(28 \%)$ & $15(28 \%)$ \\
\hline Both & $8(13 \%)$ & $6(11 \%)$ \\
\hline Duration (weeks) & $12(10-12)$ & $12(10-12)$ \\
\hline \multicolumn{3}{|l|}{ Continent } \\
\hline North America & $30(47 \%)$ & $26(48 \%)$ \\
\hline Europe & $19(30 \%)$ & $14(26 \%)$ \\
\hline Asia & $6(9 \%)$ & $6(11 \%)$ \\
\hline Australia & $3(5 \%)$ & $2(4 \%)$ \\
\hline South America & $3(5 \%)$ & $3(6 \%)$ \\
\hline Multiple & $3(5 \%)$ & $3(6 \%)$ \\
\hline \multicolumn{3}{|c|}{ Characteristics of included patients } \\
\hline Age (years) & $36(33-37)$ & $36(33-37)$ \\
\hline $\begin{array}{l}\text { Disease severity (YBOCS } \\
\text { score) }\end{array}$ & NA & $25(24-26)$ \\
\hline Comorbid depression & $27(42 \%)$ & $19(35 \%)$ \\
\hline \multicolumn{3}{|c|}{ Pharmaceutical industry sponsorship* } \\
\hline Yes & $28 / 46(61 \%)$ & $25 / 39(64 \%)$ \\
\hline No & $15 / 46(33 \%)$ & $12 / 39(31 \%)$ \\
\hline Unclear & $3 / 46(7 \%)$ & $2 / 39(5 \%)$ \\
\hline \multicolumn{3}{|c|}{ Allowed patients on antidepressant medication $†$} \\
\hline Yes & $13 / 18(72 \%)$ & $12 / 15(80 \%)$ \\
\hline No & $4 / 18(22 \%)$ & $2 / 15(13 \%)$ \\
\hline Unclear & $1 / 18(6 \%)$ & $1 / 15(7 \%)$ \\
\hline \multicolumn{3}{|c|}{$\begin{array}{l}\text { Data are } \mathrm{n} \text {, median (IQR), } \mathrm{n}(\%) \text {, or } \mathrm{n} / \mathrm{N}(\%) \text {. YBOCS=Yale-Brown Obsessive } \\
\text { Compulsive Scale. NA=Not applicable. *For pharmacological trials. } \\
\text { †For psychotherapeutic trials. }\end{array}$} \\
\hline
\end{tabular}

The 54 trials included in the network meta-analysis (quantitative review) involved 17 different treatments grouped into 12 classes (all six SSRIs were grouped into the same class; figure 2). Overall, of the 136 unique pairwise comparisons that could be made between the 17 treatment conditions, only 37 (27\%) were studied head to head in the included studies. A detailed table of the data used in the analysis is in the appendix. Six (11\%) trials used a waiting list control group: five $(9 \%)$ CBT studies ${ }^{23,31,40,50,71}$ including 157 patients, 80 (51\%) of whom had been randomly allocated to CBT, and one (2\%) behavioural 


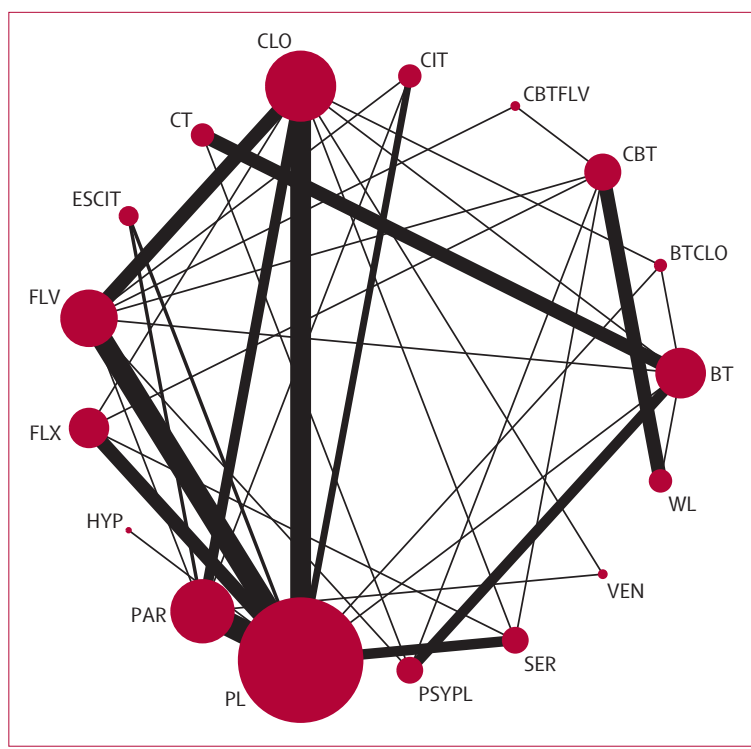

Figure 2: Network diagram for efficacy analysis representing direct comparisons between individual treatments

The size of each circle is proportional to the number of randomly allocated participants and the width of each line is proportional to the number of trials in each direct comparison. $\mathrm{BT}=$ behavioural therapy. $\mathrm{CBT}=$ cognitive behavioural therapy. $C T=$ cognitive therapy. $\mathrm{BTCLO}=$ behavioural therapy and clomipramine. CBTFLV=cognitive behavioural therapy and fluvoxamine. $C I T=$ citalopram. $\mathrm{CLO}=$ clomipramine. $\mathrm{ESCIT}=$ =scitalopram. $\mathrm{FLV}=$ fluvoxamine. $\mathrm{FLX}=$ fluoxetine $\mathrm{HYP}=$ hypericum. $\mathrm{PAR}=$ paroxetine. $\mathrm{PL}=$ placebo. $\mathrm{PSYPL}=$ psychological placebo. $S E R=$ sertraline. $V E N=$ venlafaxine. $W L=$ waiting list.

therapy study ${ }^{56}$ including 40 patients, 20 (50\%) of whom had been randomly allocated to behavioural therapy. The behavioural therapy trial that used the waiting list as a control group ${ }^{56}$ was clearly an outlier in terms of efficacy (mean YBOCS difference from waiting list at the end of study $-30 \cdot 87)$. The network meta-analysis model gave an adequate fit to the data and we identified no evidence of inconsistency (posterior mean of the residual deviance was 104.6 in the network meta-analysis assuming consistency and 105.8 assuming inconsistency compared with 107 data points). Furthermore, the deviance information criterion was similar for the models with $(480 \cdot 8)$ and without $(479 \cdot 1)$ the consistency assumption. The posterior median SD for the consistency model was 3.10 (95\% credible interval 2.46-3.95), whereas for the inconsistency model, this value was reduced to $1 \cdot 75(1 \cdot 18-2 \cdot 53)$.

Most active interventions showed a significant reduction in mean YBOCS compared with drug placebo, regardless of inclusion or exclusion of trials using waiting list controls (table 2). Venlafaxine and psychological placebo both showed reductions in mean YBOCS, but they were not significant. The waiting list was the only so-called intervention that was associated with an increase in mean YBOCS compared with drug placebo. The effects of individual SSRIs were similar in magnitude. Clomipramine had a larger effect compared with placebo than did SSRIs, but the difference was not significant (table 3). All three psychotherapeutic interventions (behavioural therapy, cognitive therapy, and CBT) showed greater efficacy than did drug placebo. However, in the full analysis, CBT was less efficacious than were the other two and was not different from psychological placebo (appendix). Exclusion of studies that had used waiting list control groups led to a larger effect for CBT, which was significantly different from psychological placebo and similar to the other two psychotherapies.

In the full network, both behavioural and cognitive therapy had a larger reduction in mean YBOCS than did SSRIs as a class (table 3). CBT also had a lower mean YBOCS than SSRIs as a class, but only after excluding waiting list controlled trials. We observed similar results when comparing different types of psychotherapies with clomipramine as the reference (detailed results for all possible comparisons are shown in the appendix). However, in psychotherapeutic trials, most patients were taking stable doses of antidepressant medications for the whole duration of the trial. The same applies to the comparison between combinations of medications and psychotherapy versus psychotherapy alone as patients in these network comparisons were not in strict monotherapy (table 2, table 3). In all of these comparisons, differences were small. Excluding waiting list controlled trials, the combination of behavioural therapy with clomipramine was associated with the largest effect, but this combination has been used in only a single trial. ${ }^{38}$

For all 64 trials included in the qualitative review, results of the risk of bias assessment for trials with at least one drug arm (46 [72\%] of 64) and those with psychotherapy arms only (18 [28\%] of 64) are presented in the appendix. Sequence generation (13 [20\%] of 64) and random allocation concealment (eight [13\%] of 64) were specifically described (ie, low risk of bias) in few studies. In trials with psychotherapy arms, masking of participants or those delivering the intervention was not possible (seven [39\%] of these 18 trials used outcome assessors who were masked to treatment allocation). In the drug only trials, specification of the double-blind method (eg, identical capsules) was described in 15 (39\%) of 38 trials. Handling of incomplete outcome data with an acceptable method was reported in 28 (61\%) of the 46 trials with at least one drug arm and six (33\%) of the 18 trials with psychotherapy arms only. A high proportion of the trials with drug arms were sponsored by pharmaceutical companies (table 1).

For the sensitivity analyses, we used the full network (detailed results given in the appendix). In the first analysis, we included the $33(61 \%)$ trials with low overall $(<25 \%)$ and differential $(<15 \%)$ attrition. This analysis led to a larger effect for CBT than in the full analysis,which was then very similar to the other two psychotherapies. In the second analysis, we included 34 (63\%) trials that met the criterion of low risk of bias in the domain of incomplete outcome assessment, and the main finding was that clomipramine had a smaller effect than in the full analysis that was not different from that of SSRIs. 
In this analysis, we excluded all cognitive therapy trials as they had reported completers analyses. In the third analysis, we included the 17 (31\%) trials that used a masked outcome assessor. Overall, results were similar to those of the full analysis, but the power was compromised because of the small sample size. We carried out separate meta-regressions to test the effect of length of trial, publication date, industry sponsorship, and inclusion of patients with current comorbid depression. The effects of these variables were small, and none were significant (appendix).

\section{Discussion}

In this network meta-analysis, we found that several pharmacological and psychotherapeutic interventions can be considered more efficacious than is drug placebo. We found that SSRIs are generally equally efficacious, with no evidence to suggest that one drug is better than the others are. Their effect compared with placebo is statistically significant, but the estimated mean difference is generally moderate. In the full analysis, clomipramine showed a trend for a larger effect than with SSRIs that was not statistically significant. This finding contrasts with previous direct analyses, which postulated that clomipramine might be more efficacious than are SSRIs. ${ }^{10}$ This comparison was sensitive to studies with incomplete outcome assessment: some old clomipramine trials reported completers analyses only, and exclusion of these trials led to a lower effect for clomipramine than that of not excluding them, which was indistinguishable from that of SSRIs.

An unexpected finding was that in our main analysis, CBT had a smaller effect than that of behavioural or cognitive therapy. However, after exclusion of waiting list controlled trials, all differences between psychotherapies were not significant. The waiting list was the only so-called intervention that led to an increase in mean YBOCS score compared with drug placebo, and psychological placebo was very similar to drug placebo after exclusion of waiting list controlled trials. Research has also shown that trials using control groups with no or minimal contact with therapists usually lead to grossly overestimated effect sizes for active psychotherapeutic interventions..$^{18,84,85}$ We obtained similar findings in the sensitivity analysis after exclusion of trials with high overall attrition to those from the main analysis after exclusion of waiting list controlled trials-ie, no difference between psychotherapies. The evidence for cognitive therapy mostly comes from trials that had compared it with behavioural therapy, with most of them not reporting intention-to-treat analyses, and these trials might have overestimated the effect of cognitive (and behavioural) therapy. The behavioural therapy trial that used the waiting list as a control group ${ }^{56}$ was clearly an outlier in terms of efficacy, and excluding it from the analysis reduced the effects for both behavioural and cognitive therapy, but not significantly. CBT has more

\begin{tabular}{|c|c|c|c|c|}
\hline & \multirow{2}{*}{$\begin{array}{l}\text { Number } \\
\text { of trials } \\
(n=54)^{*}\end{array}$} & \multirow{2}{*}{$\begin{array}{l}\text { Number of } \\
\text { patients } \\
(\mathrm{n}=6652)^{*}\end{array}$} & \multicolumn{2}{|l|}{ Mean YBOCS difference } \\
\hline & & & Full network $(n=54)$ & $\begin{array}{l}\text { Excluding waiting list } \\
\text { controlled trials }(n=48)\end{array}$ \\
\hline Drug placebo & 23 & 1515 & Reference & Reference \\
\hline Waiting list & 6 & 97 & $5.62(0.91$ to 10.26$)$ & NA \\
\hline Psychological placebo† & 6 & 196 & $-4.15(-8.65$ to 0.49$)$ & $-1.90(-5.62$ to 1.91$)$ \\
\hline SSRIs (class effect) & 37 & 3158 & $-3 \cdot 49(-5 \cdot 12$ to $-1 \cdot 81)$ & $-3 \cdot 62(-4 \cdot 89$ to $-2 \cdot 34)$ \\
\hline Fluoxetine & 6 & 633 & $-3.46(-5 \cdot 27$ to $-1 \cdot 58)$ & $-3 \cdot 67(-5 \cdot 13$ to $-2 \cdot 26)$ \\
\hline Fluvoxamine & 13 & 521 & $-3.60(-5.29$ to -1.95$)$ & $-3.66(-4.96$ to $-2 \cdot 37)$ \\
\hline Paroxetine & 8 & 902 & $-3 \cdot 42(-5 \cdot 10$ to $-1 \cdot 61)$ & $-3 \cdot 51(-4 \cdot 81$ to $-2 \cdot 14)$ \\
\hline Sertraline & 7 & 565 & $-3 \cdot 50(-5 \cdot 30$ to $-1 \cdot 63)$ & $-3 \cdot 68(-5 \cdot 14$ to $-2 \cdot 30)$ \\
\hline Citalopram & 2 & 311 & $-3 \cdot 49(-5 \cdot 62$ to $-1 \cdot 31)$ & $-3.60(-5 \cdot 25$ to $-1 \cdot 91)$ \\
\hline Escitalopram & 1 & 226 & $-3 \cdot 48(-5 \cdot 61$ to $-1 \cdot 23)$ & $-3 \cdot 59(-5 \cdot 25$ to $-1 \cdot 86)$ \\
\hline Venlafaxine & 2 & 98 & $-3 \cdot 22(-8 \cdot 26$ to 1.88$)$ & $-3.21(-7.01$ to 0.69$)$ \\
\hline Clomipramine & 13 & 831 & $-4.72(-6.85$ to $-2 \cdot 60)$ & $-4 \cdot 66(-6 \cdot 26$ to $-3 \cdot 05)$ \\
\hline $\mathrm{BT} \dagger$ & 11 & 287 & $-14 \cdot 48(-18 \cdot 61$ to $-10 \cdot 23)$ & $-10 \cdot 41(-14.04$ to -6.77$)$ \\
\hline $\mathrm{CBT} \dagger$ & 9 & 231 & $-5 \cdot 37(-9 \cdot 10$ to $-1 \cdot 63)$ & $-7.98(-11.02$ to -4.93$)$ \\
\hline Cognitive therapy $\dagger$ & 6 & 172 & $-13 \cdot 36(-18 \cdot 40$ to $-8 \cdot 21)$ & $-9 \cdot 45(-13 \cdot 76$ to $-5 \cdot 19)$ \\
\hline Hypericum & 1 & 30 & $-0.15(-7 \cdot 46$ to $7 \cdot 12)$ & $-0.13(-5.93$ to 5.68$)$ \\
\hline CBT and fluvoxamine & 1 & 6 & $-7.50(-13.89$ to -1.17$)$ & $-8.81(-13.75$ to -3.88$)$ \\
\hline BT and clomipramine & 1 & 31 & $-12 \cdot 97(-19 \cdot 18$ to $-6 \cdot 74)$ & $-11.68(-16.73$ to -6.65$)$ \\
\hline \multicolumn{5}{|c|}{$\begin{array}{l}\text { Data in parentheses are } 95 \% \text { credible intervals. YBOCS=Yale-Brown Obsessive Compulsive Scale. BT=behavioural } \\
\text { therapy. } \mathrm{CBT}=\text { cognitive behavioural therapy. } \mathrm{NA}=\text { not applicable. *Individual trials could be included in more than } \\
\text { one treatment category. } \text { Several patients randomly allocated into these psychotherapeutic interventions were } \\
\text { allowed to take stable doses of antidepressants and remain on the same dose without further adjustments. }\end{array}$} \\
\hline
\end{tabular}

\begin{tabular}{|c|c|c|}
\hline & $\begin{array}{l}\text { Mean YBOCS difference } \\
\text { in full network }(n=54)\end{array}$ & $\begin{array}{l}\text { Mean YBOCS } \\
\text { difference excluding } \\
\text { waiting list controlled } \\
\text { trials }(n=48)\end{array}$ \\
\hline SSRIs (class effect) & Reference & Reference \\
\hline Clomipramine & $-1.23(-3.41$ to 0.94$)$ & $-1.05(-2.73$ to 0.63$)$ \\
\hline $\mathrm{BT}^{*}$ & $-10 \cdot 99(-15 \cdot 14$ to $-6 \cdot 75)$ & $-6.79(-10.44$ to -3.11$)$ \\
\hline $\mathrm{CBT}^{*}$ & $-1.88(-5 \cdot 52$ to 1.76$)$ & $-4.36(-7.34$ to -1.40$)$ \\
\hline Cognitive therapy* & $-9.87(-14.91$ to -4.74$)$ & $-5 \cdot 83(-10 \cdot 17$ to $-1 \cdot 51)$ \\
\hline CBT and fluvoxamine & $-4 \cdot 03(-10 \cdot 36$ to $2 \cdot 21)$ & $-5.19(-10.09$ to -0.33$)$ \\
\hline BT and clomipramine & $-9 \cdot 48(-15 \cdot 78$ to $-3 \cdot 14)$ & $-8 \cdot 01(-13.18$ to $-2 \cdot 95)$ \\
\hline \multicolumn{3}{|c|}{$\begin{array}{l}\text { Data in parentheses are } 95 \% \text { credible intervals. YBOCS=Yale-Brown Obsessive } \\
\text { Compulsive Scale. BT=behavioural therapy. CBT=cognitive behavioural therapy. } \\
\text { *Several patients randomly allocated into these psychotherapeutic interventions } \\
\text { were allowed to take stable doses of antidepressants and remain on the same } \\
\text { dose without further adjustments. }\end{array}$} \\
\hline \multicolumn{3}{|c|}{$\begin{array}{l}\text { Table 3: Efficacy of psychological and pharmacological interventions } \\
\text { compared with SSRIs }\end{array}$} \\
\hline
\end{tabular}

links with other interventions and a more extensive network of trials than do cognitive and behavioural therapy and has been compared directly with several drugs in the same trial..$^{26,7174,75}$ Taking all of this evidence into account, our analysis does not support the view that the three types of psychotherapy have different effects in obsessive-compulsive disorder. 
Our analysis shows that all psychotherapies, either in the full dataset (for behavioural and cognitive therapy) or after exclusion of the waiting list controlled trials (for CBT), were more likely to lead to a larger effect than were medications. Some previous meta-analyses have reported similar results in favour of psychotherapy. For example, Cuijpers and colleagues $^{86}$ examined the differential effect of pharmacotherapy and psychotherapy in major depression, dysthymia, panic disorder, social anxiety disorder, and obsessive-compulsive disorder, and reported a positive effect for psychotherapy compared with medications only for obsessive-compulsive disorder. One important limitation exists that, to our knowledge, has not been recognised before: most patients included in trials that used exclusively psychotherapeutic interventions were allowed to continue taking their antidepressant medications. Combination trials that had both psychotherapeutic and drug arms, or arms with both psychotherapy and drugs, explicitly excluded patients on antidepressant medications by design (and half of these trials were of CBT and half were of behavioural therapy). Therefore, psychotherapy trials have essentially compared different psychotherapeutic interventions in patients taking stable doses of antidepressant medications. Some evidence exists from other trials that focused exclusively on treatment-refractory patients that addition of CBT for patients with SSRI-refractory obsessive-compulsive disorder is more efficacious than is either psychological placebo ${ }^{87}$ or risperidone ${ }^{88}$ In our analysis, although patients were symptomatic at study recruitment, what the effect would be if patients had been tapered off their antidepressant medication before randomisation is unknown because such studies have not been done. This issue has also been reported in meta-analyses of bipolar depression in which randomly allocated patients are allowed to continue using their mood stabilisers or anxiolytic medications. ${ }^{89}$ In any case, generalisation of these results for psychotherapeutic interventions in patients not taking concurrent antidepressant medications is difficult. Therefore, the question of what is better as monotherapy in obsessivecompulsive disorder-medications or psychotherapycannot be answered given the current evidence.

Our analysis has several limitations. Most studies were of short-term duration. As most of the studies that tested the efficacy of psychotherapeutic interventions included patients who were taking stable doses of antidepressant medications, generalisation of these results to patients not on medications is not possible. We were unable to test different doses of the same drug to investigate potential dose-response associations...$^{90}$ Because of the scarce data, we could not treat alternative dosing schemes in pharmacological trials as different nodes in the network. Several old studies only reported completers analyses, including all cognitive therapy studies, limiting the usefulness of the sensitivity analysis in this domain. We did not consider the relative efficacy of the various interventions in different symptom dimensions of obsessive-compulsive disorder, and generalisation of the results in subgroups of patients with specific symptoms, such as hoarding, should be made with caution.

The results of our analysis generally support current National Institute for Health and Care Excellence guidelines. For pharmacological management, the recommendation to use SSRIs rather than clomipramine as the first-line agents is supported by our findings since SSRIs have better tolerability than does clomipramine and we identified no convincing evidence for clomipramine being more efficacious than are SSRIs. For non-pharmacological management, all three types of psychotherapy are probably more efficacious than is non-specific therapy, but evidence is limited to patients taking stable doses of antidepressant medication before initiating psychotherapy. The combined initiation of both medication and psychotherapy (either behavioural therapy or CBT) seemed an efficacious treatment. In our analysis excluding waiting list controlled trials, this combined treatment was best, but with considerable uncertainty. Given that most psychotherapeutic trials can also be considered variants of combination trials (since most patients were taking stable doses of antidepressant medications), the combination of SSRIs or clomipramine with psychotherapy is likely to offer more benefit to patients with severe illness than is monotherapy, but more research is needed than at present to support this hypothesis, including cost-effectiveness analyses.

Further research should try to differentiate more clearly than at present the effect of medications versus psychotherapy and monotherapy versus combined therapy. Trials that investigate the effect of psychotherapy should monitor use of antidepressants in included patients or recruit patients who are willing to taper off their antidepressant medication before entering randomisation. As obsessivecompulsive disorder is a very heterogeneous condition, more pragmatic trials of longer duration than have been done so far are needed to test the efficacy of existing interventions in patients encountered in daily clinical practice (including those with other comorbid conditions) and the augmenting effect of medications in addition to psychotherapy or vice versa in patients with treatmentrefractory obsessive-compulsive disorder.

\section{Contributors}

PSk led the review, was responsible for managing the project, and drafted the report. DMC provided statistical support and did the network meta-analyses with PB. WH was a member of the review team, provided statistical support, and helped in the analysis. NAF was a member of the review team providing expert clinical advice (psychopharmacology) and helped in the writing of the report. PSa was a member of the review team providing expert clinical advice (psychotherapy). NJW provided statistical advice and helped with the statistical modelling. HB contributed to data extraction and the systematic review. DK was a member of the review team providing expert clinical advice. RC provided advice for the data searches, the systematic review, and methods. GL provided advice on the methods and systematic review and helped in writing of sections of the report. DMC, PB, NJW, and GL helped in interpretation of the results. WH, NAF, PSa, DK, RC, and GL made critical comments that helped in interpretation of the results. 


\section{Declaration of interests}

PSk has received non-financial support from Lundbeck to attend a conference during the conduct of this study. GL is a board member of the National Institute for Health Research Efficacy and Mechanism Evaluation programme. NAF reports grants and non-financial support from the National Institute for Health Research during the conduct of this study; grants and personal fees from GlaxoSmithKline and AstraZeneca; non-financial support from Novartis; personal fees and non-financial support from the European College of Neuropsychopharmacology and Bristol-Myers Squibb; grants from the Medical Research Council and Wellcome Foundation; non-financial support from Janssen, the International College of Obsessive Compulsive Spectrum Disorders, the Journal of Behavioural Addiction, and WHO; grants, personal fees, non-financial support, and reimbursed registration to attend scientific meetings from Lundbeck; informal consultation without receiving payment for Transcept Pharmaceuticals; grants, personal fees, non-financial support, and reimbursed registration to attend scientific meetings from Servier; grants, non-financial support, and reimbursed registration to attend scientific meetings from Cephalon; personal fees, non-financial support, and reimbursed registration to attend scientific meetings from Jazz Pharmaceuticals; non-financial support and reimbursed registration to attend scientific meetings from the Royal College of Psychiatrists; and non-financial support and reimbursed registration to attend scientific meeting from the British Association for Psychopharmacology, all outside the submitted work. She is also medical lead to a National Health Service service that provides treatment for treatment-refractory obsessive-compulsive and related disorders, has been a council member for the British Association for Psychopharmacology, and sits on the Royal College of Psychiatrists Psychopharmacology Special Committee and the European College of Neuropsychopharmacology Education Committee and Research Network. DMC reports grants from the Medical Research Council Population Health Scientist fellowship during the conduct of this study. All other authors declare no competing interests.

\section{Acknowledgments}

This project was funded by the National Institute for Health Research Health Technology Assessment programme (project number 10/104/41). The views and opinions expressed herein are those of the authors and do not necessarily reflect those of the Health Technology Assessment programme, National Institute for Health Research, National Health Service, or Department of Health.

\section{References}

1 Fontenelle LF, Mendlowicz MV, Versiani M. The descriptive epidemiology of obsessive-compulsive disorder. Prog Neuropsychopharmacol Biol Psychiatry 2006; 30: 327-37.

2 Macy AS, Theo JN, Kaufmann SC, et al. Quality of life in obsessive compulsive disorder. CNS Spectr 2013; 18: 21-33.

3 Meier SM, Mattheisen M, Mors O, Schendel DE, Mortensen PB, Plessen KJ. Mortality among persons with obsessive-compulsive disorder in Denmark. JAMA Psychiatry 2016; 73: 268-74.

4 Fineberg NA, Brown A, Reghunandanan S, Pampaloni I. Evidence-based pharmacotherapy of obsessive-compulsive disorder. Int J Neuropsychopharmacol 2012; 15: 1173-91.

5 Salkovskis PM. Obsessional-compulsive problems: a cognitive-behavioural analysis. Behav Res Ther 1985; 23: 571-83.

6 Abramowitz JS. The psychological treatment of obsessive-compulsive disorder. Can J Psychiatry 2006; 51: 407-16.

$7 \quad$ National Institute for Health and Care Excellence. Obsessive-compulsive disorder: core interventions in the treatment of obsessive-compulsive disorder and body dysmorphic disorder. London: National Institute for Health and Care Excellence, 2005.

8 Soomro GM, Altman D, Rajagopal S, Oakley-Browne M. Selective serotonin re-uptake inhibitors (SSRIs) versus placebo for obsessive compulsive disorder (OCD). Cochrane Database Syst Rev 2008; 1: CD001765.

9 Piccinelli M, Pini S, Bellantuono C, et al. Efficacy of drug treatment in obsessive-compulsive disorder. A meta-analytic review. Br J Psychiatry 1995; 166: 424-43.

10 Ackerman DL, Greenland S. Multivariate meta-analysis of controlled drug studies for obsessive-compulsive disorder. J Clin Psychopharmacol 2002; 22: 309-17.
11 Gava I, Barbui C, Aguglia E, et al. Psychological treatments versus treatment as usual for obsessive compulsive disorder (OCD). Cochrane Database Sys Rev 2007; 2: CD005333.

12 Caldwell DM, Ades AE, Higgins JP. Simultaneous comparison of multiple treatments: combining direct and indirect evidence. $B M J$ 2005; 331: 897-900.

13 Goodman WK, Price LH, Rasmussen SA, et al. The Yale-Brown Obsessive Compulsive Scale. I. Development, use, and reliability. Arch Gen Psychiatry 1989; 46: 1006-11.

14 Higgins JP, Green S. Cochrane handbook for systematic reviews of interventions. Version 5.0.0. Chichester: Cochrane Collaboration, 2008.

15 Dias S, Sutton AJ, Ades AE, Welton NJ. Evidence synthesis for decision making 2: a generalized linear modeling framework for pairwise and network meta-analysis of randomized controlled trials. Med Decis Making 2013; 33: 607-17.

16 Haas DM, Caldwell DM, Kirkpatrick P, McIntosh JJ, Welton NJ. Tocolytic therapy for preterm delivery: systematic review and network meta-analysis. BMJ 2012; 345: e6226.

17 Dias S, Welton NJ, Sutton AJ, Caldwell DM, Lu G, Ades AE. Evidence synthesis for decision making 4: inconsistency in networks of evidence based on randomized controlled trials. Med Decis Making 2013; 33: 641-56.

18 Honyashiki M, Furukawa TA, Noma H, et al. Specificity of CBT for depression: a contribution from multiple treatments meta-analyses. Cogn Ther Res 2014; 38: 49-60.

19 Baskin TW, Tierney SC, Minami T, Wampold BE. Establishing specificity in psychotherapy: a meta-analysis of structural equivalence of placebo controls. J Consult Clin Psychol 2003, 71: 973-79.

20 Cuijpers P, van Straten A, Bohlmeijer E, Hollon SD, Andersson G. The effects of psychotherapy for adult depression are overestimated a meta-analysis of study quality and effect size. Psychol Med 2010; 40: 211-23.

21 Albert U, Aguglia E, Maina G, et al. Venlafaxine versus clomipramine in the treatment of obsessive-compulsive disorder: a preliminary single-blind, 12 -week, controlled study. J Clin Psychiatry 2002; 63: 1004-09.

22 Ananth J, Pecknold JC, van den Steen N, et al. Double-blind comparative study of clomipramine and amitriptyline in obsessive neurosis. Prog Neuropsychopharmacol 1981; 5: 257-62.

23 Anderson RA, Rees CS. Group versus individual cognitive-behavioural treatment for obsessive-compulsive disorder: a controlled trial. Behav Res Ther 2007; 45: 123-37.

24 Andersson E, Enander J, Andrén P, et al. Internet-based cognitive behaviour therapy for obsessive-compulsive disorder: a randomized controlled trial. Psychol Med 2012; 42: 219.

25 Belloch A, Cabedo E, Carrio C. Cognitive versus behaviour therapy in the individual treatment of OCD: changes in cognitions and clinically significant outcomes at post-treatment and one-year follow-up. Behav Cogn Psychother 2008; 36: 521-40.

26 Belotto-Silva C, Diniz JB, Malavazzi DM, et al. Group cognitive-behavioral therapy versus selective serotonin reuptake inhibitors for obsessive-compulsive disorder: a practical clinical trial. J Anxiety Disord 2012; 26: 25-31.

27 Bergeron R, Ravindran AV, Chaput Y, et al. Sertraline and fluoxetine treatment of obsessive-compulsive disorder: results of a double-blind, 6-month treatment study. J Clin Psychopharmacol 2002; 22: 148-54.

28 Bisserbe JC, Lane RM, Flament MF. A double-blind comparison of sertraline and clomipramine in outpatients with obsessive-compulsive disorder. Eur Psychiaty 1997; 12: 82-93.

29 Chouinard G, Goodman W, Greist J, et al. Results of a double-blind placebo controlled trial of a new serotonin uptake inhibitor, sertraline, in the treatment of obsessive-compulsive disorder. Psychopharmacol Bull 1990; 26: 279-84.

30 Clomipramine in the treatment of patients with obsessive-compulsive disorder. The Clomipramine Collaborative Study Group. Arch Gen Psychiatry 1991; 48: 730-38.

31 Cordioli AV, Heldt E, Bochi DB, et al. Cognitive-behavioral group therapy in obsessive-compulsive disorder: a randomized clinical trial. Psychother Psychosom 2003; 72: 211-16.

32 Cottraux J, Mollard E, Bouvard M, Marks I. Exposure therapy, fluvoxamine, or combination treatment in obsessive-compulsive disorder: one-year follow up. Psychiatry Res 1993; 49: 63-75. 
33 Cottraux J, Note I, Yao SN, et al. A randomized controlled trial of cognitive therapy versus intensive behavior therapy in obsessive compulsive disorder. Psychother Psychosom 2001; 70: 288-97.

34 Denys D, van der Wee N, van Megen $\mathrm{H}$, et al. A double blind comparison of venlafaxine and paroxetine in obsessive-compulsive disorder. J Clin Psychopharmacol 2003; 23: 568-75.

35 Emmelkamp PM, Beens H. Cognitive therapy with obsessive-compulsive disorder: a comparative evaluation. Behav Res Ther 1991; 29: 293-300.

36 Emmelkamp PM, Visser S, Hoekstra RJ. Cognitive therapy vs exposure in vivo in the treatment of obsessive-compulsives. Cogn Ther Res 1988; 12: 103-14.

37 Fals-Stewart W, Marks AP, Schafer J. A comparison of behavioral group therapy and individual behavior therapy in treating obsessive-compulsive disorder. J Nerv Ment Dis 1993; 181: 189-93.

38 Foa EB, Liebowitz MR, Kozak MJ, et al. Randomized, placebo-controlled trial of exposure and ritual prevention, clomipramine, and their combination in the treatment of obsessive-compulsive disorder. Am J Psychiatry 2005; 162: 151-61.

39 Freeman CP, Trimble MR, Deakin JF, et al. Fluvoxamine versus clomipramine in the treatment of obsessive compulsive disorder: a multicenter, randomized, double-blind, parallel group comparison. J Clin Psychiatry 1994; 55: 301-05.

40 Freeston MH, Ladouceur R, Gagnon F, et al. Cognitive-behavioral treatment of obsessive thoughts: a controlled study. J Consult Clin Psychol 1997; 65: 405-13.

41 Goodman WK, Kozak MJ, Liebowitz M, et al. Treatment of obsessive-compulsive disorder with fluvoxamine: a multicentre, double-blind, placebo-controlled trial. Int Clin Psychopharmacol 1996; 11: 21-29.

42 Goodman WK, Price LH, Rasmussen SA, et al. Efficacy of fluvoxamine in obsessive-compulsive disorder. A double-blind comparison with placebo. Arch Gen Psychiatry 1989; 46: 36-44.

43 Greist JH, Jefferson JW, Kobak KA, et al. A 1 year double-blind placebo-controlled fixed dose study of sertraline in the treatment of obsessive-compulsive disorder. Int Clin Psychopharmacol 1995; 10: $57-65$.

44 Greist JH, Marks IM, Baer L, et al. Behavior therapy for obsessive-compulsive disorder guided by a computer or by a clinician compared with relaxation as a control. J Clin Psychiatry 2002; 63: 138-45.

45 GlaxoSmithKline. A double blind, multicenter, randomized, drug-controlled study to assess the efficacy and tolerance of paroxetine compared with clomipramine in treatment of obsessive compulsive disorder. Sept 28, 2008. http://www.gsk-clinical studyregister.com/files2/2097.pdf (accessed May 24, 2016).

46 GlaxoSmithKline. Paroxetine versus clomipramine and placebo in the treatment of obsessive-compulsive disorder. Sept 28, 2008. http://www.gsk-clinicalstudyregister.com/files2/2168.pdf (accessed May 24, 2016).

47 Hohagen F, Winkelmann G, Rasche-Ruchle H, et al. Combination of behaviour therapy with fluvoxamine in comparison with behaviour therapy and placebo. Results of a multicentre study. Br J Psychiatry Suppl 1998; 35: 71-78.

48 Hollander E, Allen A, Steiner M, et al. Acute and long-term treatment and prevention of relapse of obsessive-compulsive disorder with paroxetine. J Clin Psychiatry 2003; 64: 1113-21.

49 Hollander E, Koran LM, Goodman WK, et al. A double-blind, placebo-controlled study of the efficacy and safety of controlled-release fluvoxamine in patients with obsessive-compulsive disorder. J Clin Psychiatry 2003; 64: 640-47.

50 Jaurrieta N, Jimenez-Murcia S, Menchón JM, et al. Individual versus group cognitive-behavioral treatment for obsessive-compulsive disorder: a controlled pilot study. Psychother Res 2008; 18: 604-14.

51 Jenike MA, Baer L, Minichiello WE, et al. Placebo-controlled trial of fluoxetine and phenelzine for obsessive-compulsive disorder. Am J Psychiatry 1997; 154: 1261-64.

52 Jenike MA, Baer L, Summergrad P, et al. Sertraline in obsessive-compulsive disorder: a double-blind comparison with placebo. Am J Psychiatry 1990; 147: 923-28.

53 Jenike MA, Hyman S, Baer L, et al. A controlled trial of fluvoxamine in obsessive-compulsive disorder: implications for a serotonergic theory. Am J Psychiatry 1990; 147: 1209-15.
54 Jones MK, Menzies RG. Danger ideation reduction therapy (DIRT) for obsessive-compulsive washers. A controlled trial. Behav Res Ther 1998; 36: 959-70.

55 Kamijima K, Murasaki M, Asai M, et al. Paroxetine in the treatment of obsessive-compulsive disorder: randomized, double-blind, placebo-controlled study in Japanese patients. Psychiatry Clin Neurosci 2004; 58: 427-33.

56 Khodarahimi S. Satiation therapy and exposure response prevention in the treatment of obsessive compulsive disorder. J Contemp Psychother 2009; 39: 203-07.

57 Kobak KA, Taylor LV, Bystritsky A, et al. St John's wort versus placebo in obsessive-compulsive disorder: results from a double-blind study. Int Clin Psychopharmacol 2005; 20: 299-304.

58 Koran LM, McElroy SL, Davidson JR, et al. Fluvoxamine versus clomipramine for obsessive-compulsive disorder: a double-blind comparison. J Clin Psychopharmacol 1996; 16: 121-29.

59 Kronig MH, Apter J, Asnis G, et al. Placebo-controlled, multicente study of sertraline treatment for obsessive-compulsive disorder. J Clin Psychopharmacol 1999; 19: 172-76.

60 Lindsay M, Crino R, Andrews G. Controlled trial of exposure and response prevention in obsessive-compulsive disorder. Br J Psychiatry 1997; 171: 135-39.

61 López-Ibor JJ Jr, Saiz J, Cottraux J, et al. Double-blind comparison of fluoxetine versus clomipramine in the treatment of obsessive compulsive disorder. Eur Neuropsychopharmacol 1996; 6: 111-18.

62 Mavissakalian M, Turner SM, Michelson L, Jacob R. Tricyclic antidepressants in obsessive-compulsive disorder: antiobsessional or antidepressant agents? II. Am J Psychiatry 1985; 142: 572-76

63 McLean PD, Whittal ML, Thordarson DS, et al. Cognitive versus behavior therapy in the group treatment of obsessive-compulsive disorder. J Consult Clin Psychol 2001; 69: 205-14.

64 Milanfranchi A, Ravagli S, Lensi P, et al. A double-blind study of fluvoxamine and clomipramine in the treatment of obsessive-compulsive disorder. Int Clin Psychopharmacol 1997; 12: $131-36$.

65 Montgomery SA, Kasper S, Stein DJ, et al. Citalopram $20 \mathrm{mg}$ $40 \mathrm{mg}$ and $60 \mathrm{mg}$ are all effective and well tolerated compared with placebo in obsessive-compulsive disorder. Int Clin Psychopharmacol 2001; 16: 75-86.

66 Montgomery SA, McIntyre A, Osterheider M, et al. A double-blind placebo-controlled study of fluoxetine in patients with DSM-III-R obsessive-compulsive disorder. Eur Neuropsychopharmacol 1993; 3: 143-52.

67 Mundo E, Bianchi L, Bellodi L. Efficacy of fluvoxamine, paroxetine, and citalopram in the treatment of obsessive-compulsive disorder: a single-blind study. J Clin Psychopharmacol 1997; 17: 267-71.

68 Mundo E, Rouillon F, Figuera ML, et al. Fluvoxamine in obsessive-compulsive disorder: similar efficacy but superior tolerability in comparison with clomipramine. Hum Psychopharmacol 2001; 16: 461-68.

69 Nakajima T, Kudo Y, Yamashita I. Clinical usefulness of fluvoxamine maleate (SME3110), a selective serotonin reuptake inhibitor, in the treatment of obsessive compulsive disorder: a double blind, placebo controlled study. J Clin Therapeut Med 1996; 12: 409-37.

70 Nakatani E, Nakagawa A, Nakao T, et al. A randomized controlled trial of Japanese patients with obsessive-compulsive disorder-effectiveness of behavior therapy and fluvoxamine. Psychother Psychosom 2005; 74: 269-76.

71 O’Connor K, Todorov C, Robillard S, Borgeat F, Brault M. Cognitive-behaviour therapy and medication in the treatment of obsessive-compulsive disorder: a controlled study. Can J Psychiatry 1999; 44: 64-71.

72 O'Connor KP, Aardema F, Robillard S, et al. Cognitive behaviour therapy and medication in the treatment of obsessive-compulsive disorder. Acta Psychiatr Scand 2006; 113: 408-19.

73 Perse TL, Greist JH, Jefferson JW, et al. Fluvoxamine treatment of obsessive-compulsive disorder. Am J Psychiatry 1987; 144: 1543-48.

74 Shareh H, Gharraee B, Atef-Vahid M, Eftekhar M. Metacognitive therapy (MCT), fluvoxamine, and combined treatment in improving obsessive-compulsive, depressive and anxiety symptoms in patients with obsessive-compulsive disorder (OCD). Iran J Psychiatry Behav Sci 2010; 4: 17-25. 
75 Sousa MB, Isolan LR, Oliveira RR, Manfro GG, Cordioli AV. A randomized clinical trial of cognitive-behavioral group therapy and sertraline in the treatment of obsessive-compulsive disorder. J Clin Psychiatry 2006; 67: 1133-39.

76 Stein DJ, Andersen EW, Tonnoir B, Fineberg N. Escitalopram in obsessive-compulsive disorder: a randomized, placebo-controlled, paroxetine-referenced, fixed-dose, 24-week study. Curr Med Res Opin 2007; 23: 701-11.

77 Thoren P, Asberg M, Cronholm B, et al. Clomipramine treatment of obsessive-compulsive disorder. I. A controlled clinical trial. Arch Gen Psychiatry 1980; 37: 1281-85.

78 Tollefson GD, Birkett M, Koran L, et al. Continuation treatment of OCD: double-blind and open-label experience with fluoxetine. J Clin Psychiatry 1994; 55: 69-76.

79 van Oppen P, de Haan E, van Balkom AJ, Spinhoven P, Hoogduin K, van Dyck R. Cognitive therapy and exposure in vivo in the treatment of obsessive compulsive disorder. Behav Res Ther 1995; 33: 379-90.

80 Volavka J, Neziroglu F, Yaryura-Tobias JA. Clomipramine and imipramine in obsessive-compulsive disorder. Psychiatry Res 1985; 14: 85-93.

81 Whittal ML, Thordarson DS, McLean PD. Treatment of obsessive-compulsive disorder: cognitive behavior therapy vs. exposure and response prevention. Behav Res Ther 2005; 43: 1559-76

82 Whittal ML, Woody SR, McLean PD, Rachman SJ, Robichaud M. Treatment of obsessions: a randomized controlled trial. Behav Res Ther 2010; 48: 295-303.

83 Zohar J, Judge R. Paroxetine versus clomipramine in the treatment of obsessive-compulsive disorder. OCD Paroxetine Study Investigators. Br J Psychiatry 1996; 169: 468-74.
84 Furukawa TA, Noma H, Caldwell DM, et al. Waiting list may be a nocebo condition in psychotherapy trials: a contribution from network meta-analysis. Acta Psychiatr Scand 2014; 130: 181-92.

85 Watts SE, Turnell A, Kladnitski N, Newby JM, Andrews G Treatment-as-usual (TAU) is anything but usual: a meta-analysis of CBT versus TAU for anxiety and depression. J Affect Disord 2015 175: 152-67.

86 Cuijpers P, Sijbrandij M, Koole SL, Andersson G, Beekman AT, Reynolds CF 3rd. The efficacy of psychotherapy and pharmacotherapy in treating depressive and anxiety disorders: a meta-analysis of direct comparisons. World Psychiatry 2013; 12: $137-48$

87 Simpson HB, Foa EB, Liebowitz MR, et al. A randomized, controlled trial of cognitive-behavioral therapy for augmenting pharmacotherapy in obsessive-compulsive disorder. Am J Psychiatry 2008; 165: 621-30.

88 Simpson HB, Foa EB, Liebowitz MR, et al. Cognitive-behavioral therapy vs risperidone for augmenting serotonin reuptake inhibitors in obsessive-compulsive disorder: a randomized clinical trial. JAMA Psychiatry 2013; 70: 1190-99.

89 Taylor DM, Cornelius V, Smith L, Young AH. Comparative efficacy and acceptability of drug treatments for bipolar depression: a multiple-treatments meta-analysis. Acta Psychiatr Scand 2014; 130: 452-69.

90 Bloch MH, McGuire J, Landeros-Weisenberger A, Leckman JF, Pittenger C. Meta-analysis of the dose-response relationship of SSRI in obsessive-compulsive disorder. Mol Psychiatry 2010; 15: 850-55. 